\title{
Interlink between Obesity Hypoventilation Syndrome and Obstructive Sleep Apnea. Do we need to screen patients for OHS in obese OSA patients?
}

\author{
Dhakal SS ${ }^{1}$, Maskey $\mathrm{R}^{2}$, Bhattarai $\mathrm{M}^{3}$ \\ ${ }^{1}$ Department Of Internal Medicine, Kathmandu Medical College and Teaching Hospital, Sinamangal, \\ Kathamandu, ${ }^{2}$ B.P.Koirala Institute of Health Sciences, Dharan, ${ }^{3}$ Kathmandu Medical College and \\ Teaching Hospital, Sinamangal, Kathamndu.
}

\begin{abstract}
:
Introduction: Around 90\% of patients with OHS have coexistent obstructive sleep apnea (OSA) defined by an apnea-hypopnea index (AHI) $>5$ events/h, with nearly $70 \%$ having severe OSA (AHI $>$ 30 events/h). 3 Prevalence of OHS is between $8 \%$ and $20 \%$ in obese patients referred to sleep centers for evaluation of SDB. As prevalence of OHS in OSA patients dats from Nepal is not available we planned to carry out the study and to address gaps in diagnosis and management. Methodology: This is a cross sectional observational study done in OM hospital and research centre from 2018 January to 2019 June. Awake daytime Arterial blood gas( $\mathrm{ABG}$ )was obtained and patients having $\mathrm{PaCO} 2$ more than $45 \mathrm{mmHg}$ were diagnosed as obesity hypoventilation syndrome in a recently diagnosed patients with OSA. Results: 32 patients diagnosed to have OSA and whose BMI is more than 30 were included in the study. Among 32 patients $26(81.25 \%)$ were male and $6(18.75)$ were female.Among all patients who underwent level A polysomnography $3(12.5 \%)$ had mild OSA,4(16.66\%) had moderate and $17(53.12 \%)$ had severe OSA. 8 (25\%)patients had normal diagnostic polysomnography. Among these patients $3(12.5 \%)$ who had mild OSA has BMI between 30-35,16 (66.66\%) patients who had BMI between 30-35,2 had mild 3 had moderate and 11 had severe OSA. Patients with BMI more than 40,5(28.3\%) had OSA among which 21 had moderate and 4 had severe OSA. Conclusions: As OHS is often misdiagnosed even in patients with severe obesity, we strongly recommended screening in obese patients with OSA for OHS as early recognition and effective treatment are important in improving morbidity and mortality in this group of patients.
\end{abstract}

Key Words: Interlink, Obesity hypoventilation syndrome, OSA

\section{Introduction:}

Obesity hypoventilation syndrome (OHS) is commonly defined as a combination of obesity (BMI $>30 \mathrm{~kg}$ per $\mathrm{m} 2$ ) and waking arterial hypercapnia $(\mathrm{Pa}, \mathrm{CO} 2>45 \mathrm{mmHg}){ }^{1,2}$ Approximately $90 \%$ of patients with OHS have coexistent obstructive sleep apnea (OSA) defined by an apnea-hypopnea index (AHI) $>5$ events $/ \mathrm{h}$, with nearly $70 \%$ having severe OSA (AHI $>30$ events $/ \mathrm{h}){ }^{3}$ Prevalence of OHS is between $8 \%$ and $20 \%$ in obese patients referred to sleep centers for evaluation of SDB. ${ }^{4,5,6,7}$ As the

\section{Corresponding Author:}

Dr. Subodh Sagar Dhakal, Department Of Internal Medicine, Kathmandu Medical College and Teaching Hospital, Sinamangal, Kathamandu, Email: dhakalsubodh22@gmail. com, Phone: +977-9840066356. prevalence of obesity is unknown in the general population and obesity is a strong predictor for OSA and to address gaps in diagnosis and management and improve patient-centered outcomes we carry out the study to look for OHS in obese patients with body mass index more than 30 and already diagnosed to have OSA.

\section{Methodology:}

This is a cross sectional observational study done in OM hospital and research centre from 2018 January to 2019 June.All the patients who were to have obstructive sleep apnea and whose BMI is more than 30 were enrolled for the study. To grade the severity of sleep apnea, the number of events 
per hour is reported as the apnea-hypopnea index (AHI). An AHI of less than 5 is considered normal. An AHI of 5-15 is mild; $15-30$ is moderate and more than 30 events per hour characterizes severe sleep apnea. ${ }^{6}$

Awake daytime Arterial blood gas( $\mathrm{ABG}$ )was obtained and patients having $\mathrm{PaCO} 2$ more than 45 $\mathrm{mmHg}$ were diagnosed as obesity hypoventilation syndrome. Patient with obstructive or restrictive lung diseases were excluded from the study. Convenience sampling was done and minimum sample size was calculated as \% of OHS in OSA4. The total sample for the study was 32 . Bias present in the study such as selection bias and interviewer's bias were minimized as possible. All the data were collected and entry was done in Microsoft excel. Point estimate at 95\% CI was done along with frequency and proportion for binary data.

\section{Results:}

32 patients diagnosed to have OSA and whose BMI is more than 30 were included in the study. Daytime $\mathrm{ABG}$ in an awake state is done in all the individuals. Patients having PCO2 more than 45 were diagnosed as OHS. Among 32 patients enrolled for the study 21 had hypertension and 12 had type 2 diabetes for which they were taking regular medications.

Table 1. Baseline characteristics of patients

\begin{tabular}{|l|l|l|}
\hline Gender & Number & Percentage \\
\hline Male & 26 & $81.25 \%$ \\
\hline Female & 6 & 18.75 \\
\hline Age & & \\
\hline $20-40$ & 20 & $62.5 \%$ \\
\hline $40-60$ & 10 & $31.25 \%$ \\
\hline$>60$ & 2 & $6.25 \%$ \\
\hline BMI & & \\
\hline$>30-<35$ & 9 & $28.12 \%$ \\
\hline$\geq 35-<40$ & 16 & $50 \%$ \\
\hline$>40$ & 7 & $21.87 \%$ \\
\hline Severity of OSA & & \\
\hline AHI 5-15 & 3 & $12.5 \%$ \\
\hline AHI more than $15-30$ & 4 & $16.66 \%$ \\
\hline More than 30 & 17 & $53.12 \%$ \\
\hline Normal: less than 5 & 8 & $25 \%$ \\
\hline
\end{tabular}

Among 32 patients 24 had OSA among which 3 (12.5\%) had mild,4(16.66\%) had moderate and $17(70.83 \%)$ had severe OSA .It was seen more in male $(79.16 \%)$ than female $(20.83 \%)$.

Table 2: OHS in OSA patients:

\begin{tabular}{|l|l|l|}
\hline Total & Number with OHS & Percentage \\
\hline Male & 19 & $79.16 \%$ \\
\hline Female & 5 & $20.83 \%$ \\
\hline \hline
\end{tabular}

Table 3: Interlink of OHS with OSA according to body mass index (BMI):

\begin{tabular}{|l|l|l|}
\hline BMI & OHS (Number with \%) & Severity of OSA \\
\hline $30-35$ & $3(12.5 \%)$ & $\begin{array}{l}\text { Mild :1 } \\
\text { Moderate }: 0 \\
\text { Severe }: 2\end{array}$ \\
\hline More than & $16(66.66 \%)$ & Mild: 2 \\
$35-40$ & & $\begin{array}{l}\text { Moderate }: 3 \\
\text { Severe }: 11\end{array}$ \\
\hline More than 40 & $5(20.83 \%)$ & $\begin{array}{l}\text { Mild : } 0 \\
\text { Moderate: } 1 \\
\end{array}$ \\
& & Severe : 4 \\
\hline
\end{tabular}

Patient with BMI between 30-35, 3(12.5\%) patients had OHS among which 1 had mild and 2 had severe OSA. Patient with BMI between 35-40,16 (66.66\%) had OHS among which 2 had mild, 3 had moderate and 11 had severe obstructive sleep apnea.Patients with BMI above 40, 5 (20.83\%) had OHS among which 1 had moderate and 4 had severe OSA.

\section{Discussion}

Despite the availability of effective therapies, most patients with OHS remain undiagnosed and untreated until late in the course of the disease when they present to high-acuity settings with acute-onchronic hypercapnic respiratory failure.$^{8,9}$ During this delay, patients with OHS use more healthcare resources than eucapnic patients of comparable obesity. ${ }^{10} \mathrm{OHS}$ misfortunately is misdiagnosed even in patients with severe obesity who are hospitalized with hypercapnic respiratory failure.$^{11}$

Early recognition and effective treatment are 
important in improving morbidity and mortality. Two-thirds of OSA patients are obese, particularly with android type obesity. Obesity is associated with many other medical conditions including sleep-disordered breathing.

The role of obesity as a risk factor for the development of obstructive sleep apnoea (OSA) is well established. ${ }^{12}$ For example, two studies performed in South America reported that over $80 \%$ of morbidly obese patients had OSA. ${ }^{12,13}$ In addition, a recent study performed in primary care in the UK in adults older than 50 years reported that subjects with a BMI of $40 \mathrm{~kg} / \mathrm{m} 2$ or over were 27.39 times (95\% CI 24.64-30.46) more likely to have OSA $(\mathrm{p}<0.0001) .{ }^{14}$

Male gender and increasing age are also considered as risk factorsforOSA. ${ }^{15}$ OSA is one of the most common sleep disorders which can occur on similar incidence to that of type II diabetes and twice than that of asthma. ${ }^{16}$ In the UAE, the prevalence of OSA in the adult population has been estimated to be around $7 \%$. In our study male patients number was higher than female, this may be due to the fact that OSA is more common in male than female and in our part of the world male seek medical attention more than female. $15>50 \%$ of severely obese patients (BMI $>40 \mathrm{~kg}$ per $\mathrm{m} 2$ ) are affected by severe OSA .17In our study also 24 out of 32 patients had OHS.Among patients with BMI greater than 40 maximum(4) out of 7 patients had severe obstructive sleep apnea and 1 had moderate obstructive sleep apnea.Multiple studies have reported a prevalence of OHS between $8 \%$ and $20 \%$ in obese patients referred to sleep centers for evaluation of SDB which is lower than seen in our study. ${ }^{4-7}$ But in other studies $90 \%$ of patients with OHS have coexistent obstructive sleep apnea (OSA)defined by apneahypopneaindex (AHI) $>5$ events $/ \mathrm{h}$, with nearly $70 \%$ having severe OSA (AHI $>30$ events $/ \mathrm{h}$ ). 18 In general, a prevalence of $5 \%$ is typically seen in patients with SDB with BMI of 30 to $34.9 \mathrm{~kg} / \mathrm{m} 2$, $10 \%$ is typically seen in patients with BMI of 35 to $40 \mathrm{~kg} / \mathrm{m} 2$, and $20 \%$ is seen in patients with BMI $.40 \mathrm{~kg} / \mathrm{m} 2 .{ }^{4}$ In a metaanalysisdone by Chaoling
Liu et al among 575 patients (28\%) with Obesity Hypoventilation Syndrome were diagnosed from 2085 Obstructive Sleep Apnea patients. ${ }^{19}$ This also highlights the importance of screening for OHS in OSA patients.It is important for clinical doctors to differentiate OHS and OSA when making a diagnosis. OHS is an exclusionary diagnosis while OSA can be diagnosed by polysomnography.

\section{Conclusion}

In a resource poor settings like Nepal where sleep studies facilities are available only in few places, patients who are obese and having OSA, simple tests like ABG to screen for OHS are needed. As OHS is often misdiagnosed even in patients with severe obesity. We strongly recommended screening in obese patients with OSA for OHS as early recognition and effective treatment are important in improving morbidity and mortality in this group of patients.

\section{Conflict of interest:None}

\section{Reference:}

1. Olson AL, Zwillich C. The obesity hypoventilation syndrome. Am J Med 2005; 118: 948-956.

2. Randerath W, Verbraecken J, Andreas S, Arzt M, Bloch KE, Brack T, et al. Definition, discrimination, diagnosis and treatment of central breathing disturbances during sleep. EurRespir J 2017;49:1600959.

3. Masa JF, Corral J, Alonso ML, Ordax E, Troncoso MF, Gonzalez M, et al.; Spanish Sleep Network. Efficacy of different treatment alternatives for obesity hypoventilation syndrome: Pickwick study. Am J RespirCrit Care Med 2015;192:86-95.

4. Balachandran JS, Masa JF, Mokhlesi B. Obesity hypoventilation syndrome epidemiology and diagnosis. Sleep Med Clin 2014;9: 341-347.

5. Harada Y, Chihara Y, Azuma M, Murase K, ToyamaY,Yoshimura C, etal.; Japan Respiratory Failure Group. Obesity hypoventilation syndrome in Japan and independent determinants of arterial carbon dioxide levels. Respirology2014;19:1233-1240.

6. BaHammam AS. Prevalence, clinical 
characteristics, and predictors of obesity hypoventilation syndrome in a large sample of Saudi patients with obstructive sleep apnea. Saudi Med J 2015;36:181-189.

7. Kaw R, Hernandez AV, Walker E, Aboussouan L, Mokhlesi B. Determinants of hypercapnia in obese patients with obstructive sleep apnea: a systematic review and metaanalysis of cohort studies. Chest 2009;136:787-796.

8. Lee WY, Mokhlesi B. Diagnosis and management of obesity hypoventilation syndrome in the ICU. Crit Care Clin 2008;24: 533-549, vii.

9. Carrillo A, Ferrer M, Gonzalez-Diaz G, Lopez-Martinez A, Llamas N, Alcazar $\mathrm{M}$, et al. Noninvasive ventilation in acute hypercapnic respiratory failure caused by obesity hypoventilation syndrome and chronic obstructive pulmonary disease. Am J RespirCrit Care Med 2012;186:1279-1285.

10. Berg G, Delaive K, Manfreda J, Walld R, Kryger MH. The use of healthcare resources in obesity-hypoventilation syndrome. Chest 2001; 120:377-383.

11. Marik PE, Chen C. The clinical characteristics and hospital and posthospital survival of patients with the obesity hypoventilation syndrome: analysis of a large cohort. ObesSciPract2016;2:40-47.

12. Valencia-Flores $\mathrm{M}$, Orea A, Castano VA, Resendiz M, Rosales M, Rebollar $\mathrm{V}$, et al. Prevalence of sleep apnea and electrocardiographic disturbances in morbidly obese patients. Obes Res 2000; 8(3): 262-269.
13. Daltro C, Gregorio PB, Alves E, Abreu M, Bomfim D, Chicourel MH, et al. Prevalence and severity of sleep apnea in a group of morbidly obese patients. Obes Surg 2007; 17(6): 809-814.

14. Wall H, Smith C and Hubbard R. Body mass index and obstructive sleep apnoea in the UK: a crosssectional study of the over-50s. Prim Care Respir J 2012; 21(4): 371-376.

15. Young T, Palta M, Dempsey J, Skatrud J, Weber S and Badr S. The occurrence of sleepdisordered breathing among middle-aged adults. N Engl J Med 1993; 328(17): 12301235.

16. Sankri-Tarbichi AG. Obstructive sleep apneahypopnea syndrome: etiology and diagnosis. Avicenna J Med 2012; 2(1): 3-8. 7. Olson AL and Zwillich C. The obesity hypoventilation syndrome. Am J Med 2005; 118(9): 948-956.

17. Resta O, Foschino-Barbaro MP, Legari G, et al. Sleep-related breathing disorders, loud snoring and excessive daytime sleepiness in obese subjects. Int J ObesRelatMetabDisord 2001; 25: 669-675.

18. Masa JF, Corral J, Alonso ML, Ordax E, Troncoso MF, Gonzalez M, et al.; Spanish Sleep Network. Efficacy of different treatment alternatives for obesity hypoventilation syndrome: Pickwick study. Am J RespirCrit Care Med 2015;192:86-95.

19. Chaoling Liu1, Mao-Sheng Chen2 and Hui Yu1.Oncotarget, 2017, Vol. 8, (No. 54), pp: 93168-93178. 